\title{
Resources and population served: a description of the Ontario Paediatric Diabetes Network
}

\author{
Rayzel Shulman MD, Fiona A. Miller PhD, Therese A. Stukel PhD, Denis Daneman MBBCh DSc(Med), \\ Astrid Guttmann MDCM MSc
}

\section{Abstract}

Background: The Network of Ontario Pediatric Diabetes Programs was established in 2001 to provide access to specialized pediatric diabetes care. Universal funding for pediatric insulin pump therapy has been available in Ontario since 2006. The objective of this study was to describe the distribution of patients, resources and insulin pump use across centres within the network, now called the Ontario Paediatric Diabetes Network.

Methods: We conducted a cross-sectional survey in 2012 of the 35 pediatric diabetes centres in Ontario to measure centre characteristics, patient volume and available clinical and social resources. We used health administrative data from the provincial Assistive Devices Program to describe patients aged 18 years or less using insulin pumps by centre as a measure of technology uptake.

Results: All 35 centres participated, reporting a total of 6676 children with type 1 diabetes and 368 with type 2 diabetes. Most (> $80 \%$ ) children with type 1 diabetes were followed at tertiary $(n=5)$ or large community $(n=14)$ centres. Nursing patient load was similar between centre types, but there was a large range across centres within any type. Overall, percent insulin pump use was $38.1 \%$ and varied widely across centres (5.3\%-66.7\%). Funded 24-hour support for pump users was available at 5 (36\%) small community centres, $3(19 \%)$ large community centres and $2(40 \%)$ tertiary centres.

Interpretation: Our study showed differences in access to specialized and after-hours care for children with diabetes in Ontario. Pump use varied widely across centres. Further research is needed to assess the impact of these observed differences on quality of care and outcomes.

anada has one of the world's highest incidence rates of type 1 diabetes mellitus among children (25.9 per 100000 per year), ${ }^{1}$ and the incidence is increasing by $3 \%$ annually. ${ }^{2,3}$ Given the short- and long-term consequences of diabetes starting in childhood, ${ }^{4}$ there is a need for a system with the capacity to provide high-quality care. Although guidelines for the delivery of ambulatory diabetes care to children and adolescents with diabetes have been established, ${ }^{5-7}$ evidence linking particular aspects of care delivery to important diabetes outcomes is lacking. ${ }^{8-12}$ Therefore, it is not surprising that there is marked heterogeneity in the organization and provision of services for pediatric diabetes care, as is reported in Europe. ${ }^{13-15}$ In Canada, the provinces have responsibility for most of the delivery of health care services. Nova Scotia and Ontario are the only provinces that have a dedicated pediatric diabetes network.

In 2001, the Network of Ontario Pediatric Diabetes Programs was established under the mandate of the Northern Diabetes Health Network to improve access to specialized pediatric diabetes care for all children in Ontario. ${ }^{16}$ As of 2013/14, the Ontario Paediatric Diabetes Network (OPDN) is coordinated by the Provincial Council for Maternal and Child Health, a program of the Ministry of Health and Long-Term Care. ${ }^{17}$ The OPDN currently comprises 35 centres, including 30 community and 5 tertiary centres, each employing physicians, nurses, dietitians and social workers with training in diabetes care. All core diabetes services and, since 2006, funding for insulin pumps and $75 \%$ of the cost of pump supplies for all children aged 18 years or less with type 1 diabetes are provided universally by the Ontario Ministry of Health and Long-Term Care.

Competing interests: None declared.

This article has been peer reviewed.

Correspondence to: Astrid Guttmann, astrid.guttmann@ices.on.ca CMAJ Open 2016. DOI:10.9778/cmajo.20150006 
The rate of pump use and its distribution across centres since the introduction of universal funding has not been described. It is not known whether there are barriers to pump use related to centre resources or practice patterns. The unique setup of this coordinated network of care for children with type 1 diabetes is ideal for collecting data to study and improve the quality and outcomes of pediatric diabetes care. The objective of this study was to describe and compare the distribution of patient load and resources across centre types within the OPDN. We also describe percent pump use as a measure of technology uptake. These data are needed to examine whether variation in centre resources is associated with management and/or outcomes of pump use. This information can then be used to inform the design of interventions aimed at improving quality of care.

\section{Methods}

We performed a cross-sectional descriptive study of all 35 pediatric diabetes centres in Ontario (Appendix 1, available at www.cmajopen.ca/content/4/2/E141/suppl/DC1) using survey and administrative health data. Research ethics board approval was obtained from the University of Toronto, The Hospital for Sick Children and Sunnybrook Hospital.

\section{Questionnaire design}

We collected data using a self-completed questionnaire designed to identify specific centre characteristics, patient volume by type of diabetes, and the clinical and social support resources available (Appendix 2, available at www.cmajopen. $\mathrm{ca} /{ }^{\prime}$ ontent/4/2/E141/suppl/DC1). We asked the centres to report the number of full-time-equivalent members of the diabetes team who provide comprehensive care at the centre. We asked about the training of physicians providing care and provision of funded 24-hour support for patients using insulin pumps. We captured data on mean hemoglobin $\mathrm{A}_{\mathrm{cc}}\left(\mathrm{HbA}_{\mathrm{cc}}\right)$ values for all children with type 1 diabetes at each centre. $\mathrm{HbA}_{\mathrm{lc}}$ values have been shown to vary within and between jurisdictions and have been used as a measure of the quality of care. ${ }^{8,18}$ The mean $\mathrm{HbA}_{1 \mathrm{c}}$ level for each centre was selfreported, and no correction for assay differences was made.

The questionnaire was developed based on previous systemwide surveys of adult diabetes ${ }^{19}$ and asthma ${ }^{20}$ education centres in Ontario, with input from key informants (specialist physicians and experienced nurses) on both the content and style of questions. As well, we presented the study objectives and methods at the annual OPDN meeting in November 2010 and invited feedback. In addition, before the annual OPDN meeting in November 2011, we met with the OPDN advisory committee to get feedback on the survey.

\section{Survey administration}

We mailed the questionnaire to the responsible diabetes nurse or dietitian at each Ontario pediatric diabetes centre, identified from a publicly available directory, within 1 week of our presentation at the OPDN meeting in November 2011. Clinical team members were expected to have access to the infor- mation requested; if not, they were directed to consult an administrator. We collected data from November 2011 to March 2012 using a modified Dillman method. ${ }^{21}$ Centres that did not respond were contacted up to 6 times via telephone or email, in 2-week intervals from the time the questionnaires were mailed. This procedure was continued until all of the centres had responded.

\section{Data elements}

We defined centre type by categorizing the centres according to whether they were a tertiary or community centre and by patient volume. The 5 tertiary centres are located in the major pediatric academic health science centres in Ontario's major cities (Toronto, Ottawa, London, Hamilton and Kingston). We defined small community centres as those with a patient volume less than 100 and large community centres as those with a patient volume of 100 or more. We assigned a community size index, based on 2006 census population data, to each centre using the centre's postal code. Centres located in communities with a population less than 500000 were considered rural, and those in communities with a population of 500000 or more were considered urban. We measured the farthest distance reported by centres that patients travelled to get to their centre.

The model of physician care at each centre was defined as pediatric endocrinologist, generalist (general pediatrician[s] or family physician [s] but no pediatric endocrinologist) or generalist with a visiting pediatric endocrinologist.

To describe centre resources, we calculated patient load by dividing the full-time equivalent for each of nurse, dietitian and social worker by the total number of patients with type 1 and type 2 diabetes at each centre. In addition, we identified centres that reported having any full-time equivalent psychologists, child life specialists or psychiatrists, and having telemedicine available.

We used available provincial administrative health data to determine the proportion of children with type 1 diabetes at each centre who were using insulin pumps. We used claims data from the Assistive Devices Program, available at the Institute for Clinical and Evaluative Sciences (an independent, not-for-profit organization that, through a comprehensive data-sharing agreement with the Ontario Ministry of Health and Long-Term Care, conducts health services research for Ontario). Initial Assistive Devices Program forms are completed at the time of application for pump funding and identify the centre where the patient receives his or her diabetes care. To determine the number of patients at each centre using pump therapy in 2012, we counted the number of patients who had ever had an initial approved application for pump funding minus any patient who had turned 19, had moved out of province or had discontinued pump funding as of Jan. 1, 2012. We calculated percent pump use in 2012 by dividing the number of patients using pump therapy at each centre with a volume of patients with type 1 diabetes of 6 or more ( $n=33$ centres), divided by the total number of patients with type 1 diabetes at a given centre. 


\section{Statistical analysis}

Descriptive statistics were performed with the use of SAS Enterprise 6.1 software and are reported by centre type.

\section{Results}

We report the data elements for which we had the highest response rates and that were of the highest quality. Table 1 shows centre characteristics and resources by centre type. Of the 7044 patients seen at Ontario pediatric diabetes centres, $6676(94.8 \%)$ had type 1 diabetes, the majority of whom were followed at large community $(41.0 \%)$ or tertiary $(40.8 \%)$ centres. Most large (64\%) and small (69\%) community centres were located in rural areas, and most tertiary centres $(60 \%)$ were located in urban areas. All tertiary centres were staffed by pediatric endocrinologists, large community centres had a mix of physician models, and small community centres were staffed mostly by generalists and visiting pediatric endocrinologists. More than half of all centres had telemedicine available.

Overall, the median patient load per nurse, dietitian and social worker was 244, 395 and 527, respectively (Table 2). None of the centres had a psychiatrist. Psychologists were not available at community centres, and only $40 \%$ of tertiary centres had any full-time-equivalent psychologist.

The median $\mathrm{HbA}_{\mathrm{lc}}$ level for all centres was 8.6\% (Table 3). Overall, the mean percent pump use was $38.1 \%$ (range $5.3 \%-$ $66.7 \%)$. Nine centres (26\%) had centre-specific eligibility criteria for initiation of insulin pump use.

\section{Interpretation}

This population-based study describes the resources available across the OPDN. We observed variation across centres in availability of resources and services for children with diabetes, including diabetes nurses, dietitians and social workers, and in availability of 24-hour support. There are very few centres with a psychologist and none with a psychiatrist on the diabetes care team. Finally, we found variation in glycemic control, pump use and use of centre-specific eligibility criteria for pump therapy across centres.

In Ontario, tertiary centres were staffed exclusively by pediatric endocrinologists, and the model of care differed substantially between centre types. Overall, 29\% of the centres provided 24-hour clinical support for patients using insulin pump therapy. This rate is lower than that reported for 2008 for the United Kingdom, 44\%. ${ }^{13}$ Although we report availability of funded 24-hour support for patients using pumps, our clinical experience suggests that centres that provide this service are likely to do so for all patients regardless of their insulin regimen.

Further study of the relation between centre characteristics, including model of physician care and provision of 24-hour support, and performance, while taking into account centre- and patient-level confounders, is needed to inform optimal resource allocation and team approach.

Patients travelled the farthest to tertiary centres, even though most centres had access to telemedicine services. Further work to explore how this service is being used and its asso-

\begin{tabular}{|c|c|c|c|}
\hline \multirow[b]{2}{*}{ Characteristic } & \multicolumn{3}{|c|}{ No. $(\%)$ of centres ${ }^{*} \dagger$} \\
\hline & $\begin{array}{l}\text { Large community } \\
\text { centres } \\
(n=14)\end{array}$ & $\begin{array}{c}\text { Small community } \\
\text { centres } \\
(n=16)\end{array}$ & $\begin{array}{l}\text { Tertiary centres } \\
\quad(n=5)\end{array}$ \\
\hline $\begin{array}{l}\text { Patients with type } 1 \text { diabetes, no. (\%) } \\
(n=6676)\end{array}$ & $2739(41.0)$ & $1211(18.1)$ & $2726(40.8)$ \\
\hline $\begin{array}{l}\text { Patients with type } 2 \text { diabetes, no. (\%) } \\
(n=368)\end{array}$ & $169(45.9)$ & $102(27.7)$ & $97(26.4)$ \\
\hline \multicolumn{4}{|l|}{ Physician model of care } \\
\hline Generalist & $4(29)$ & $8(50)$ & $0(0)$ \\
\hline Pediatric endocrinologist & $5(36)$ & $1(6)$ & $5(100)$ \\
\hline Visiting pediatric endocrinologist & $5(36)$ & $6(38)$ & $0(0)$ \\
\hline Unknown & $0(0)$ & $1(6)$ & $0(0)$ \\
\hline \multicolumn{4}{|l|}{ Community type } \\
\hline Rural (population < 500 000) & $9(64)$ & $11(69)$ & $2(40)$ \\
\hline Urban (population $\geq 500000$ ) & $5(36)$ & $3(19)$ & $3(60)$ \\
\hline Unknown & $0(0)$ & $2(12)$ & $0(0)$ \\
\hline $\begin{array}{l}\text { Farthest distance travelled to centre, } \mathrm{km} \text {, } \\
\text { median (IQR) }\end{array}$ & $\begin{array}{c}100(70-108) \\
\quad n=12\end{array}$ & $\begin{array}{c}100(60-200) \\
\quad n=15\end{array}$ & $350(200-388)$ \\
\hline Telemedicine available & $9(64)$ & $11(69)$ & $3(60)$ \\
\hline
\end{tabular}




\section{OPEN}

Research

ciation with management and outcome of diabetes is important to inform optimal use of this technology within the OPDN.

In Europe in 2009, 80\% of the smallest pediatric diabetes care centres and all of the largest centres had a diabetes nurse educator. ${ }^{14}$ In the United Kingdom in 2008, 94\% of centres had a diabetes specialist nurse, $88 \%$ of whom worked solely in pediatrics. ${ }^{13}$ In the European study, the number of patients per nurse ranged from 140 to 184 across centre size, ${ }^{14}$ and in the UK study, the median was $92,{ }^{13}$ considerably lower than that in the Ontario network. In the UK, 93\% of clinics reported having a pediatric dietitian, and only $21 \%$ had a psychologist. ${ }^{13}$ The OPDN has been instrumental in ensuring that each pediatric diabetes centre has a multidisciplinary core team. ${ }^{22}$ However, the median patient load of diabetes nurse specialists was 244; this exceeds recommendations of the UK Royal College of Nurses $(70: 1)^{23}$ and a European guideline $(100: 1) .^{24}$

We found that the patient load of social workers was relatively higher at large community centres than at the other centre types. Further exploration is needed to understand whether this disparity is due to variation in need for social work services based on centre type and its association with outcomes. None of the centres had any full-time-equivalent psychiatrists, and only $40 \%$ of tertiary centres had any fulltime-equivalent psychologist. Child life specialists were mostly available at tertiary centres. Further work to elucidate the availability of these professionals from outside the OPDN for consultation and ongoing care of children with diabetes is needed to assess the quality of access to these important resources.

The mean $\mathrm{HbA}_{\mathrm{lc}}$ levels reported by Ontario centres were similar to levels reported by pediatric and adult regional and national type 1 diabetes registries for 2010-2013 (median $7.4 \%-9.4 \%$ across countries and age groups). ${ }^{25}$ Patient-level data are needed to control for known confounders of glycemic control and to make meaningful between-centre comparisons.

Pump use in Ontario appears to be comparable to that in other countries such as Germany and Austria, where $41 \%$ of

Table 2: Patient load, by centre type

\begin{tabular}{|c|c|c|c|c|}
\hline Variable & $\begin{array}{l}\text { All centres } \\
(n=35)\end{array}$ & $\begin{array}{l}\text { Large community } \\
\text { centres } \\
(n=14)\end{array}$ & $\begin{array}{l}\text { Small community } \\
\text { centres } \\
(n=16)\end{array}$ & $\begin{array}{l}\text { Tertiary centres } \\
\quad(n=5)\end{array}$ \\
\hline Patients per nurse, median (IQR) & $\begin{array}{c}244(195-275) \\
\quad n=33\end{array}$ & $248(203-291)$ & $\begin{array}{c}262(197-275) \\
n=14\end{array}$ & $195(177-218)$ \\
\hline Patients per dietitian, median (IQR) & $\begin{array}{c}395(293-403) \\
n=33\end{array}$ & $398(307-403)$ & $\begin{array}{c}373(284-405) \\
n=14\end{array}$ & $363(293-397)$ \\
\hline Patients per social worker, median (IQR) & $\begin{array}{c}527(405-635) \\
\quad n=33\end{array}$ & $538(488-694)$ & $\begin{array}{c}480(367-600) \\
n=14\end{array}$ & $390(379-635)$ \\
\hline Any FTE psychologist, no. (\%) of centres & $\begin{array}{c}2(6) \\
n=32\end{array}$ & $\begin{array}{c}0(0) \\
n=13\end{array}$ & $\begin{array}{c}0(0) \\
n=14\end{array}$ & $2(40)$ \\
\hline Any FTE psychiatrist, no. (\%) of centres & $\begin{array}{c}0(0) \\
n=32\end{array}$ & $\begin{array}{c}0(0) \\
n=13\end{array}$ & $\begin{array}{c}0(0) \\
n=14\end{array}$ & $0(0)$ \\
\hline $\begin{array}{l}\text { Any FTE child life specialist, no. (\%) of } \\
\text { centres }\end{array}$ & $\begin{array}{l}5(17) \\
n=30\end{array}$ & $\begin{array}{c}0(0) \\
n=11\end{array}$ & $\begin{array}{l}2(14) \\
n=14\end{array}$ & $3(60)$ \\
\hline
\end{tabular}

Table 3: Glycemic control and insulin pump use, by centre type

\begin{tabular}{|c|c|c|c|c|}
\hline Variable & $\begin{array}{l}\text { All centres } \\
(n=35)\end{array}$ & $\begin{array}{l}\text { Large community } \\
\text { centres } \\
(n=14)\end{array}$ & $\begin{array}{l}\text { Small community } \\
\text { centres } \\
(n=16)\end{array}$ & $\begin{array}{l}\text { Tertiary centres } \\
\quad(n=5)\end{array}$ \\
\hline $\begin{array}{l}\text { Patients with type } 1 \text { diabetes using pump } \\
\text { therapy, \%, mean (range) }\end{array}$ & $\begin{array}{l}38.1(5.3-66.7) \\
\quad n=33\end{array}$ & $41.4(28.7-66.7)$ & $\begin{array}{l}34.6(5.3-65.6) \\
\quad n=14\end{array}$ & $38.7(27.8-55.0)$ \\
\hline $\begin{array}{l}\text { Centre-specific eligibility criteria for pump } \\
\text { therapy, no. (\%) of centres }\end{array}$ & $\begin{array}{l}9(26) \\
n=34\end{array}$ & $4(29)$ & $\begin{array}{l}2(12) \\
n=15\end{array}$ & $3(60)$ \\
\hline
\end{tabular}


children under 18 years of age were using pump therapy in 2010-2012. ${ }^{26}$ Data collected in regional and national registries (2010-2013) for children and adults with type 1 diabetes showed wide variation in pump use both between and within populations. ${ }^{25}$ In Ontario, pump use at each centre type appeared similar; however, there was marked variation in percent pump use between individual centres. Although this variation may have been related to differences in patient characteristics between centres, we are unable to examine these differences using available data. Furthermore, more than a quarter of all centres had centre-specific eligibility criteria for pump therapy. This suggests that there are likely differences in team philosophy and approach to pump therapy that may be contributing to the observed variation in pump use across centres and that warrant further study.

\section{Strengths and limitations}

A strength of our study is the $100 \%$ response rate and the availability of population-based data on insulin pump use. However, the fact that the data were self-reported is a limitation. We did not independently verify answers, but an internal survey in 2013 by the OPDN showed close correlation of mutual data elements. ${ }^{22}$ The method used by each centre for calculating the mean $\mathrm{HbA}_{\mathrm{cc}}$ level was not specified, nor was any correction made for differences in assay methods between centres. Finally, we measured applications for insulin pump funding, not actual pump use. Therefore, it is possible that some patients who applied for pump funding were not using a pump, and, conversely, that others who did not apply for funding via the government program were using a pump covered by private insurance or payment out of pocket. However, given the expense of the pump and the move of private insurers to not cover the cost since universal funding was introduced, the latter limitation is unlikely. In addition, some patients who applied for pump funding may have been using pump therapy before the introduction of universal funding.

\section{Conclusion}

Although the OPDN is highly structured, some centres are resourced below international guidelines, and variation exists in patient use of new technology and $\mathrm{HbA}_{\mathrm{lc}}$ levels. Future work should include the collection of patient-level data to enable studies of comparative effectiveness around differences in resources and models of care and the impact of these observed differences on diabetes quality of care and outcomes to inform Ontario and other jurisdictions.

\section{References}

1. IDF diabetes atlas. 6th ed. Brussels: International Diabetes Federation; 2013. Available: https://www.idf.org/sites/default/files/EN_6E_Atlas_Full_0.pdf (accessed 2016 Apr. 8).

2. DIAMOND Project Group. Incidence and trends of childhood type 1 diabetes worldwide 1990-1999. Diabet Med 2006;23:857-66.

3. Patterson CC, Dahlquist GG, Gyürüs E, et al. Incidence trends for childhood type 1 diabetes in Europe during 1989-2003 and predicted new cases 2005-20: a multicentre prospective registration study. [see comment]. Lancet 2009;373:2027-33.

4. Diabetes Control and Complications Trial Research Group. Effect of intensive diabetes treatment on the development and progression of long-term complications in adolescents with insulin-dependent diabetes mellitus: Diabetes Control and Complications Trial. 7 Pediatr 1994;125:177-88.
5. Wherrett D, Huot C, Mitchell B, et al. Type 1 diabetes in children and adolescents. Can 7 Diabetes 2013;37(Suppl 1):S153-62.

6. Silverstein J, Klingensmith G, Copeland K, et al. Care of children and adolescents with type 1 diabetes: a statement of the American Diabetes Association. Diabetes Care 2005;28:186-212.

7. Pihoker C, Forsander G, Wolfsdorf J, et al. The delivery of ambulatory diabetes care: structures, processes, and outcomes of ambulatory diabetes care. Pediatr Diabetes 2008;9:609-20.

8. de Beaufort CE, Lange K, Swift PG, et al. Metabolic outcomes in young children with type 1 diabetes differ between treatment centers: the Hvidoere Study in Young Children 2009. Pediatr Diabetes 2013;14:422-8.

9. Rosenbauer J, Dost A, Karges B, et al. Improved metabolic control in children and adolescents with type 1 diabetes: a trend analysis using prospective multicenter data from Germany and Austria. Diabetes Care 2012;35:80-6.

10. Svensson J, Johannesen J, Mortensen HB, et al. Improved metabolic outcome in a Danish diabetic paediatric population aged $0-18 \mathrm{yr}$ : results from a nationwide continuous Registration. Pediatr Diabetes 2009;10:461-7.

11. Doggen K, Debacker N, Beckers D, et al. Care delivery and outcomes among Belgian children and adolescents with type 1 diabetes. Eur 7 Pediatr 2012; 171:1679-85.

12. Nordly S, Mortensen HB, Andreasen AH, et al. Factors associated with glycaemic outcome of childhood diabetes care in Denmark. Diabet Med 2005;22: 1566-73.

13. Gosden C, Edge JA, Holt RI, et al. The fifth UK paediatric diabetes services survey: Meeting guidelines and recommendations? Arch Dis Child 2010;95:837-40.

14. Cinek O, Sumník Z, de Beaufort C, et al. Heterogeneity in the systems of pediatric diabetes care across the European Union. Pediatr Diabetes 2012;13 (Suppl 16):5-14.

15. Hawkes CP, Murphy NP. Paediatric type 1 diabetes in Ireland - results of the first national audit. Ir Med 7 2014;107:102-4.

16. Griffis S, Beauvais C. A system-wide response to diabetes: networks meet the challenge. Can 7 Diabetes 2007;31:16-7.

17. Paediatric Diabetes Network Working Group - terms of reference. Toronto: Provincial Council for Maternal and Child Health; 2013.

18. Peterson A, Hanberger L, Akesson K, et al. Improved results in paediatric diabetes care using a quality registry in an improvement collaborative: a case study in Sweden. PLoS One 2014;9:e97875.

19. Cauch-Dudek K, Victor JC, Sigmond M, et al. Disparities in attendance at diabetes self-management education programs after diagnosis in Ontario, Canada: a cohort study. BMC Public Health 2013;13:85.

20. Garvey NJ, Stukel TA, Guan J, et al. The association of asthma education centre characteristics on hospitalizations and emergency department visits in Ontario: a population-based study. BMC Health Serv Res 2014;14:561.

21. Dillman D. Mail and internet surveys: the tailored design method. Hoboken (NJ): Wiley; 2007.

22. Ontario Paediatric Diabetes Network current state survey report. Toronto: Provincial Council for Maternal and Child Health; 2013.

23. Specialist nursing services for children and young people with diabetes. London (UK): Paediatric and Adolescent Diabetes Group of the Royal College of Nursing; 2006. Available: https://www.rcn.org.uk/-/media/royal-college-ofnursing/documents/publications/2006/february/pub-003015.pdf (accessed 2016 Apr. 12)

24. de Beaufort C, Vazeou A, Sumnik Z, et al. Harmonize care to optimize outcome in children and adolescents with diabetes mellitus: treatment recommendations in Europe. Pediatr Diabetes 2012;13(Suppl 16):15-9.

25. McKnight JA, Wild SH, Lamb MJ, et al. Glycaemic control of type 1 diabetes in clinical practice early in the 21 st century: an international comparison. Diabet Med 2015;32:1036-50.

26. Sherr J, Hermann JM, Campbell F, et al. Use of insulin pump therapy in children and adolescents with type 1 diabetes and its impact on metabolic control: comparison of results from three large, transatlantic paediatric registries. Diabetologia 2016;59:87-91.

Affiliations: Department of Pediatrics (Shulman, Daneman, Guttmann), The Hospital for Sick Children, University of Toronto; Institute of Health Policy, Management and Evaluation (Shulman, Miller, Stukel, Guttmann), University of Toronto; Institute for Clinical Evaluative Sciences (Shulman, Stukel, Guttmann); Toronto Health Economics and Technology Assessment (THETA) Collaborative (Miller), University of Toronto, Toronto, Ont.

Contributors: Rayzel Shulman conceptualized and designed the study, designed the data collection instrument, collected the data, carried out the initial analyses, contributed to data analysis and interpretation, and drafted the initial manuscript. Fiona Miller conceptualized and designed the study and contributed to data interpretation. Therese Stukel conceptualized and designed the study and contributed to data analysis and interpretation. Denis Daneman conceptualized and designed the study and contributed to data interpretation. Astrid Guttmann conceptualized and designed the study, secured the funding, contributed to data analysis 
and interpretation, and revised the manuscript. All of the authors critically reviewed the manuscript, approved the final version to be published and agreed to act as guarantors of the work.

Funding: Rayzel Shulman received salary support from the Canadian Child Health Clinician Scientist Program. Astrid Guttmann receives salary funding from a Canadian Institutes of Health Research Applied Chair in Child Health Services and Policy Research. The administrative data analysis was supported in part by a Creative Professional Activities grant from the Department of Pediatrics, The Hospital for Sick Children. This study was supported by the Institute for Clinical Evaluative Sciences (ICES).
Disclaimer: This study was supported by the Institute for Clinical Evaluative Sciences (ICES), which is funded by an annual grant from the Ontario Ministry of Health and Long-Term Care (MOHLTC). The opinions, results and conclusions reported in this article are those of the authors and are independent from the funding sources. No endorsement by ICES or the Ontario MOHLTC is intended or should be inferred.

Supplemental information: For reviewer comments and the original submission of this manuscript, please see www.cmajopen.ca/content/4/2/ E141/suppl/DC1 